\title{
Suicid som psykiskt olycksfall: ett systemperspektiv ${ }^{1}$
}

\author{
Av Jan Beskow
}

\begin{abstract}
“Självmordet kom så plötsligt! Ingen hade väntat sig det av honom! I varje fall inte just nu!” Denna upplevelse är vanlig. Fast den stämmer dåligt med bilden av den suicidala processen, som ett långsamt framväxande beslut som verkställs avsiktligt och välplanerat? Kanske är det så - åtminstone ibland - att vissa intryck väcker så starka emotioner att personen inte kan hantera dem? Kanske är det så att suicid ibland inte är högsta grad av kontroll utan tvärtom total kontrollförlust? I så fall skulle vissa suicid kunna vara psykiska olycksfall?
\end{abstract}

I definitioner av suicid är medveten avsikt att dö centrala begrepp (Mehlum, 1999, s. 22). Suicid är en kontrollerad handling. Olyckor däremot orsakas av många brister, som inte har gått att samtidigt kontrollera. Suicidpreventionen har hämtat praktiska metoder från olycksfallspreventionen (Clarke, 1989), t ex blisterförpackningar av läkemedel, skydd på broar och åtgärder inom tågtrafiken (Beskow, 1994; Rådbo, 2008) dock utan att influeras av den teoretiska utvecklingen inom olycksfallsforskningen. Man har inte på allvar ställat frågan: Kan självmord vara olycksfall?

När jag för 25 år sedan arbetade med dessa frågor föreföll det mig att den linjära modellen av den suicidala processen måste kombineras med en fältmodell: "A still more probable model, however, is that previous experiences have created a predisposition within a person, which at certain combinations of external strain explodes in a suicidal act or better in a suicidal catastrophee" (Beskow, 1983). Skillnaden från den vanliga sårbarhetsmodellen ligger i orden "Besides that, however, a multitude of other factors, often difficult to identify and superficially perceived as chance factors are in action."

En sådan modell öppnar för möjligheten att vissa suicid kan vara psykiska olycksfall, d v s uppstå i en kognitivt okontrollerbar situation, t ex en oväntad skilsmässa kombinerad med alkoholbruk, när alltför starka psykiska krafter kommer på en person alltför snabbt för att hon skall kunna hantera dem. (Med kognitioner menas perceptioner, minnen, kroppsförnimmelser, känslor, bilder, tankar och handlingsplaner.) På samma sätt kan ett fysiskt olycksfall, t ex en trafikolycka, definieras som en situation när alltför starka fysiska krafter kommer på en person alltför snabbt för att hon skall kunna hantera dem.
Syftet med denna artikel är att visa hur modern suicidforskning inspirerad av kognitiv och beteendeinriktad terapi, KBT, alltmer närmar sig en systemmodell och hur erfarenheter inom olycksfallsforskningen kan berika förståelsen av suicidalitet samt att via en fall-illustration visa hur man med stöd av dessa kunskaper kan analysera korta intensiva suicidala episoder med förhöjd suicidrisk.

\section{Frisk suicidalitet är normal och nyttig}

Suicidalitet (tidigare suicidalt beteende) består av suicidtankar, suicidförsök och suicid. Att tänka på suicid är normalt.

Det gör alla. Att sådana tankar kan vara nyttiga och fylla viktiga uppgifter är svårare att ta till sig. Här är tre exempel:

a) Tonåringar brottas med de stora livsfrågorna. Möjligheten att ta sitt liv är en viktig del i en realistisk dödsuppfattning. Att inkludera denna möjlighet i sin livsföreståelse, men likafullt aktivt välja livet ökar livsintensitet och meningsupplevelse;

b) Överväldigande problem följda av ångest och depression leder ofta till handlingsförlamning. Tanken på suicid öppnar en utväg och gör nästa steg möjligt;

c) Suicidtankar vägleder en terapeut rakt in mot patientens viktigaste livsproblem.

Suicidalitet har ett betydande överlevnadsvärde. När jag går ut på en balkong på 10:e våningen i ett höghus och ser upp åt eller framåt känner jag, och nästan alla andra, frihet, styrka och överblick. När jag ser neråt, känns det som jag sögs ner i djupen. Ibland ser jag också inre bilder av hur jag ligger krossad och blödande på marken. Därefter kommer tre oroande tankar i så snabb följd att det krävs extra uppmärksamhet för att urskilja dem:
a) "Tänk om jag trillar ner!"
b) (som är ännu mer ångestfull)
“Tänk om jag hoppar!”
c) “Nej, det gör jag inte!"

Exemplet illustrerar snabbheten i kognitiva suicidala processer och deras koppling till ångest. Viktigast är tanke b). Genom att se suicidiet som möjlighet övergår jag från att vara offer (det bara händer) till att bli aktör (jag kontrollerar situationen). Kan jag hoppa, kan jag också låta bli. Häri ligger suicidtankarnas överlevnadsvärde. Varefter jag tar ett litet steg bakåt, håller mig i räcket eller lugnar ner mig med tanken att någon fara faktiskt inte föreligger. Detta är ett livbevarande genetiskt mönster, vars ursprungliga funktion troligen är att varna för branta klippstup. Generellt riktar den friska suicidaliteten uppmärksamheten mot olika former av hot mot livet. Om problemen inte går att lösa kvarstår suicidtankarna som en varningssignal, personen ältar dem, de stelnar och kan övergå till livsfarlig psykopatologi, till sjukdom. "Att tänka på suicid är normalt, att ha suicid som sin enda tanke är onormalt" (Shneidman, 1985; Jobes, 2006).

\section{Nya rön av KBT-inspirerade forskare}

Suicidalitet är en kognitiv process skild från den depressiva. Suicidalitet handlar om att hitta en utväg ur en intolerabel situation, att värdera livets mening eller meningslöshet, för att till sist planera och genomföra ett suicid. Denna uppfattning om suicidalitet som en övervägande kognitiv process har fătt stöd av Williams (2006), som visat att recidiv i depression kan visa en betydande symtomvariation medan suicidaliteten återkommer på likartat sätt. Nödvändigheten av att uppfatta suicidalitet och depression som skilda processer har nyligen fått stöd i en stor epidemiologisk studie (Casey, 2008).

Problemlösning. Med ovanstående bakgrund är det begripligt att terapeuter ofta fokuserat på att öka personens problemlösande förmåga, dock utan övertygande framgång. Förklaringen kom från Teasdale (1988), som visade att suicidala

1) Tack till Stiftelsen Gunnar \& Märta Bergendahl som genom ett forskningsanslag gjort studien möjlig. 


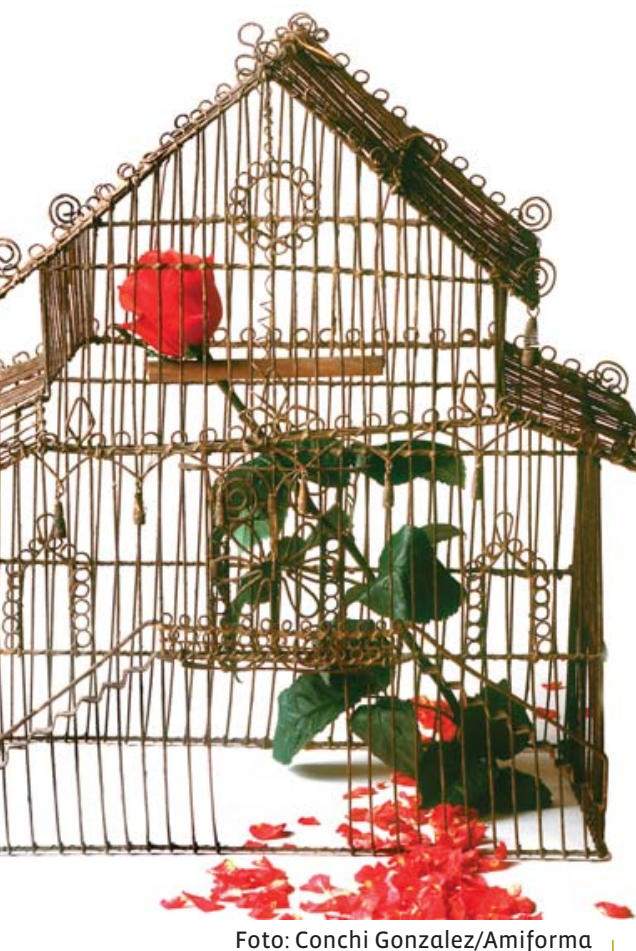

personer har en sänkt problemlösningsförmåga framför allt när de är suicidala, bekräftat av Williams (2005). Orsaken är lätt att inse. Att ha medvetandet fullt av ångest och dödstankar ger inte mycket energi över till annat tänkande. Risken för att tänka fel är kraftigt ökad. Suicidaliteten som skulle öka fokus på problemet, motverkar nu i själva verket problemlösningen.

"Suicidal mode". KBT-perspektivet (Clark, 1999) är på väg att revolutionera psykoterapeutisk och psykiatrisk analys och behandling. En viktig insikt är att rädsla, ångest och nedstämdhet är normala funktioner för att upptäcka, bearbeta och lösa problem. KBT fokuserar på vad som gör att problemen inte löses och varför ångesten och depressionen vidmakthålls och övergår i psykopatologi. Framgångarna i förståelse och behandling av framför allt ångestoch depressionstillstånd har varit betydande medan framgångarna vid behandling av patologisk suicidalitet ännu är begränsade (Beskow, 2009). Däremot har det skett en teoretisk utveckling som fört förståelsen nästan ända fram till ett systemtänkande (Ellis, 2006).

Beck (1996) introducerade det generella begreppet mode. Dessa består av tidigare i livet förvärvade komplex av scheman (mönster) bestående av kroppsförnimmelser, känslor, bilder, tankar och handlingsberedskaper. Dessa utlöses av specifika hot (triggers) mot personen och samverkar i snabba och väl samordnade åtgärder för att avvärja hotet. För personen betydelsefulla men ur omvärldens perspektiv ofta banala incitament kan trigga ett sådant suicidal mode, och resultera i en suicidal episod med förhöjd suicidrisk, som ibland utageras i suicidförsök eller suicid (Rudd, 2000). Ur personens perspektiv upplevs detta som suicidtankar eller suicidala impulser. Dessa kan även uppträda i form av inre bilder av det kommande suicidiet, påminnande om flashbacks och betecknade som flashforwards (Holmes, 2007). Impulsernas normala funktion är att informera personen om att hennes aktuella problem nu är livshotande (jämför balkongscenen ovan) och att hon nu aktivt måste kontrollera också själva suicidaliteten. Hon hamnar då i ambivalens, som ibland går över till grubbel eller ältande om liv, livets meningslöshet och självmordets nödvändighet. Forskaren och klinikern måste därför skilja mellan långvarig kronisk, latent eller baslinje-suicidalitet, orsakad av ett"suicidal mode" och korta intensiva suicidala episoder, utlöst genom att detta mode plötsligt aktiveras (Rudd, 2006). Bedömningen av dessa två olika former av patologisk suicidalitet kräver olika samtalsteknik och skattningsskalor. Rudd (2001) anger metoder för analyser av suicidala episoder, inklusive grafisk beskrivning av episoden och skattning av olika faktorers intensitet i skalor från 0-10.

En positiv effekt av det suicidala "modets" lättaktivering är att suicidala episoder kan utlösas experimentellt av t ex sorgsen musik och sedan analyseras och behandlas i icke suicidalt skede (Williams, 2005). Analys av ett ögonblick kan bli vägledande för en hel terapi (Stern, 2005).

Suicidalitetens språk är bristfälligt. Tankarna är vårt inre språk. Vi tänker med de ord och i de sammanhang vi lärt oss den omgivande kulturen. Tabueringen av suicid har medfört en massiv hämning av språkutvecklingen. Suicidalitets språk är därför torftigt (Beskow, 2005). Detta försvårar för den suicidala personen. Hon har inte ord för det hon upplever, vilket ökar paniken. Detta gäller också läkare och psykiatrer som inte har ett utvecklat språk för det suicidala skeendet inom patienten. Suicidalitetens språk behöver bli mer nyanserat och på ett begripligt sätt anknyta till olika former av hot, förluster och kränkningar, men också till ångest-och depressionssjukdom.
Nya rön från olycksfallsforskning

Efter att olycksfallsforskarna länge arbetat utifrån ett personperspektiv började de på 1970-talet anlägga ett systemperspektiv (Waller, 1980). Först då kom de stora framgångarna. Teoretiskt gick man från sekvens- eller processmodeller över multifaktoriella modeller till systemiska interaktiva modeller (Hollnagel, 2004). Det handlade inte längre bara om vad en person gör eller inte gör utan hur hon interagerar med teknik, t ex sin bil, och omgivande system, t ex våra trafikregler. Skador uppkommer genom att många komponenter $i$ komplexa system under kort tid snabbt interagerar med varandra och okontrollerat spränger systemets toleransgränser (Rasmussen, 2006).

På suicidalitet däremot anlägger forskare, psykiatrer och psykoterapeuter oftast ett personperspektiv. Suicidalitet ses som symtom på en psykisk störning, oftast depression. Behandling av denna är en viktig suicidpreventiv metod, och det med rätta. I studier av suicidalitet tillämpas oftast enkelt linjära eller multifaktoriella (epidemiologiska) modeller, t ex när man försöker identifiera riskfaktorer. Frågan är om vi nu är redo att komplettera detta med ett systemperspektiv, dvs studiet av snabba interaktiva processer under kort tid? Skall nu de stora framgångarna komma?

Kognitionernas samanbrott. Inom olycksfallsforskningen finns en klar medvetenhet om olycksfall som kognitivt misslyckande. Man har inte kunnat hantera snabbt uppkomna starka fysiska hot. Detta återkommer till och med i namnet på en välkänd analysmetod, som nått stora framgångar inom processindustri och flyg. Namnet CREAM betyder nämligen Cognitive Reliability and Error Analysis Method (Hollnagel, 1998). När denna metod nu används för att studera trafikolycksfall kallas den DREAM, Driver's Reliability and Error Analysis Method (Ljung, 2007). Med båda dessa metoder analyseras ett stort antal olyckor och olyckstillbud, varefter tabeller för kvalitativa och kvantitativa skattningar upprättas. Systemen är öppna och tabellerna revideras och utvidgas med ny kunskap. Beskrivningarna datorregistreras och analyseras. Avsikten är att identifiera återkommande mönster och kostnadseffektiva åtgärder. 


\section{SCREAM - ett projekt med fokus på suicidala episoder}

Inspirerade av dessa metoder har vi startat ett projekt med namnet SCREAM, Suicidal Cognition's Reliability and Error Analysis Method, med en referens till Mark Williams (2001), som påpekat att det inte handlar om ett "rop på hjälp" utan ett "skrik av smärta", "a scream of pain” (O’Connor, 2003). SCREAM bygger på tanken att suicidala kognitioner har ett rationellt överlevnadsvärde. De är dock inte alltid pålitliga. Därför måste vi fokusera på de relativt korta intensiva suicidala episoderna och försöka förstå hur felen i tänkandet uppstår. I CREAM och DREAM har forskarna tagit fram metoder som gör det möjligt att samla en stor mängd data om enskilda olycksfall och tillbud. Vår avsikt är att försöka åstadkomma något liknande för suicidala episoder.

\section{Fall-illustration}

Nästa steg var att försöka tillämpa principer och metoder från KBT och olycksfallsprevention på enskilda suicidala episoder. Vi genomförde därför en pilotstudie omfattande fyra suicidala episoder hos samma person.

Syftet med fall-illustrationen var att undersöka om en fokusering på akuta episoder var praktiskt genomförbar, om det gav något nytt samt göra erfarenheter av betydelse för fortsatt metodutveckling.

Försöksperson, Fp. Detta var en 53 årig kvinna, gift med två barn och forskare inom teknisk design. I tonåren hade hon en längre period med ångest/depressionssjukdom och ett allvarligt suicidförsök, men var därefter psykiskt frisk och utan suicidalitet i 30 år. Efter en nära anhörigs död insjuknade hon med tinnitus, som gick över till depression, för vilken hon varit $75 \%$ sjukskriven i åtta år. Under dessa år hade hon trots behandling med anxiolytika, antidepressiva, Litium, neuroleptika och sömnmedicin ständiga suicidtankar av varierande intensitet och gjorde flera suicidförsök. Hon tog kontakt med mig, JB, då hon hade ett trängande behov att tala om sin suicidalitet, något hennes psykiater inte vågade samtala öppet med henne om.
Metod. Under en suicidal episod plågas den utsatta personen av emotionellt tumult med psykisk smärta (psychache), vrede, hopplöshet, självförakt, skuld, skam, främlingskap samt oförmåga att sätta ord på och därigenom själv kunna kontrollera sina tankar, känslor och impulser. Trots detta är hon suicidpreventionens viktigaste aktör. Till sist är det hon som bestämmer. Hon måste därför själv successivt öka sin förmåga att hantera sina suicidala situationer.

En grupp välrenommerade suicidforskare konstaterade nyligen att bemötandet av suicidala patienter är ungefär lika i hela västerlandet och mer kliniker-än patientcentrerat. Utifrån kliniska erfarenheter och befintlig forskning summerade de vad som behöver förbättras (Michel, 2002). Kliniker bör bli mer medvetna om patientens inre upplevelser av psykisk plåga och förlust av självrespekt. Kollaborativa och narrativa metoder kan hjälpa den suicidala personen att återta förmågan att hantera sin suicidalitet. "Det är" an increasing need for qualitative research focusing on the patients' own internal suicidal processes."

En utveckling i liknande riktning är "guided self-dialogue" vid posttraumatisk stress disorder, PTSD. Terapeuten ber patienten koncentrera sig på sitt inre samtal med sig själv och terapeuten hjälper henne att göra detta mer konstruktivt (Foa, 1998, s. 202.)

Genomförande. Vi avstod från att återskapa en detaljerad helhetsbild av Fp:s livshistoria och kroniska suicidalitet. Övriga omständigheter inklusive orsaker till suicidalitetens ursprungliga uppkomst samt testningar med tre olika skattningsskalor utgjorde bara bakgrundsdata. Jag var varken psykiater eller terapeut även om samtalen innehåll terapeutiskt verksamma delar.

Efter flera orienterande samtal för att lära känna varandra och skapa trygghet koncentrerade vi oss på fyra episoder av akut suicidalitet. Fp fick konkret, specifikt och detaljerat berätta om sina inre upplevelser och interaktioner med omgivningen. Intervjuerna bandades inte utan JB skrev ner dem så detaljerat som möjligt, varefter formuleringarna bollades mellan oss tills båda var nöjda. Fp bidrog med sin unika kunskap om sin suicidalitet och tillhöriga relevanta omständigheter. JB bidrog med sina erfarenheter, teorier och möjliga tekniker med vars hjälp hon skulle kunna lära sig att hantera sin situation. Vi fungerade således som "två forskare" (Kelly, 1955) som gemensamt försökte förstå oss på hennes akuta suicidala episoder.

Därefter konstruerade vi gemensamt en liuräddningsskala enligt välkända KBTprinciper för självskattning av ångest (Öst, 2006, s. 94-97).

\section{Resultat}

Dessa är preliminära då materialet ej är helt färdigbearbetat.

\section{Fyra suicidala episoder:}

Tunnelbanan. Fp har varit på ett tröttsamt sammanträde. På vägen ner till tunnelbanan ser hon en blomsteruppsättning, som förändras. Hon har svårt att uppfatta de enskilda blommorna. Hon får allt svårare att se, allt blir dimmigt. Hon kan inte läsa skyltar tydligt, har svårt fatta deras innebörd. Hon angrips samtidigt av sina suicidtankar, vilka förvärras av frestande närhet till tåg och räls. Hon klarar dock situationen genom att koncentrera sig på en handling i sänder och lyckas välja rätt perrong och rätt tåg. Efter c:a 2 timmar blir hon lugnare.

Konstmuseet. Under en period av svår trötthet och depression besöker hon en konstutställning som visar akvareller av konstnärens döende far. Bilderna tränger in i henne, det blir mörkt och hon attackeras av "dämoner", dvs suicidtankar. På vägen ut ur museet passerar hon ett mörkt rum med en stor projicerad videobild av en penna som snurrar runt som om hon försökte penetrera underlaget. Hon lyckas dock ta sig ut ur museet och hem. Där lägger hon sig på sängen, som är en fristad utan hotfulla suicidmöjligheter. Efter ett par timmars inre kamp orkar hon ringa en vän, varefter det hela klingar av.

Musiken. Denna episod föregås av att hon lyssnar på sorgsen "skärande" rysk musik. Därefter ser hon en film om ungdomar som vårdas efter suicidförsök. Deras skärsår påminner henne plågsamt om hennes egen skärning som tonåring. Under natten kommer en liknande attack 
som tidigare. Hon beslutar sig dock för att ta sig till sin arbetsplats där hon dock bara kan uträtta lite rutinarbete. Tittar ut genom höghusets fönster som ett möjligt suicidsätt. Kan inte tala med någon av arbetskamraterna. Mot slutet av dagen får hon ett mejl av en väninna som hon har förtroende för. Sänder SMS till henne: "Nu lämnar jag jobbet", "Nu är jag på bussen”, "Nu är jag hemma”. Bara att sända iväg ett SMS lindrar plågan.

Påbörjat suicidförsök. Mörkret och suicidtankarna föregicks denna gång av tre misslyckade försök att få kontakt med andra för henne betydelsefulla personer. Hon kan inte tala om sina påträngande suicidtankar och det blockerar kontakterna. Hon blir besviken över att hon trots ett halvt års samtal om suicidtankarna ännu inte kan bemästra dem. Efter en lång- lugn och börjar nästan automatiskt förbereda sitt sedan länge planerade suicid. Avbryts dock av en nära anhörig som kommer på oanmält besök. Blir glad över att bli räddad. Episoden tar sammanlagt 2 1/2 dygn.

Konstruktion av en personlig livräddningsskala. Vi valde att göra skalan tämligen detaljerad med en 0 -nivå och tio nivåer från lägsta till högsta grad av suicidalitet, dock med tanke att senare kunna korta ner den. Varje nivå säkrades med en upplevd "ankarpunkt" och förseddes med användbara kopingstrategier. Syftet var att Fp skulle ha denna lättillgänglig för att i tid kunna bromsa ökande suicidrisk. Högre än nivå 5 får hon aldrig komma, då måste hon slå till alla bromsar. Skalans nuvarande men ännu preliminära form och utan ankarpunkter framgår av tabell 1.

Tabell 1: Förkortad Preliminär Livräddningsskala, Version 4

\begin{tabular}{|c|c|c|}
\hline Nivå & Konkreta situationer & Kopingstrategier \\
\hline 1 & $\begin{array}{l}\text { Suicidtankar då } \\
\text { och då }\end{array}$ & $\begin{array}{l}\text { Behandla depression och trötthet, ej utsätta } \\
\text { mig för påfrestningar. Självanalys. }\end{array}$ \\
\hline 2 & $\begin{array}{l}\text { Tänker på suicid } \\
\text { varje dag }\end{array}$ & $\begin{array}{l}\text { Självanalys, berätta om tankarna för vänner } \\
\text { eller expert. Bryt ensamheten. Undvik och var } \\
\text { uppmärksam på självvald isolering. Skydda } \\
\text { mig mot ökad stimulusmängd och specifika } \\
\text { utlösande faktorer. Skydda mina relationer, } \\
\text { aktivt relationsarbete när det finns risk för } \\
\text { besvikelser. }\end{array}$ \\
\hline $3-8$ & $\begin{array}{l}\text { Synsvårigheter } \\
\text { Begynnande mörker } \\
\text { Dämonerna anfaller } \\
\text { Suicidplanen aktiveras } \\
\text { Kampen intensifieras } \\
\text { Totalt mörker }\end{array}$ & $\begin{array}{l}\text { Lämna stimuliplatsen. Fokusera på en uppgift, } \\
\text { som att ta mig hem. Upprätta kontakt med } \\
\text { någon annan person genom SMS eller telefon. } \\
\text { Bara vara medvetet närvarande: Nu sitter } \\
\text { jag här, stolen är röd. Sätt ett namn på } \\
\text { dämonerna, reflektera över vad som hänt. } \\
\text { Normalisera händelsen och acceptera min } \\
\text { egen känslighet. Bara stå emot mm }\end{array}$ \\
\hline 9 & Fast i mörkret & $\begin{array}{l}\text { Söka mig till sängen, som fungerar som en } \\
\text { mental och fysisk frizon, här finns inga } \\
\text { suicidredskap. Fortsatt kamp för att upprätta } \\
\text { kontakt med någon annan person. }\end{array}$ \\
\hline 10 & Bortom all hjälp & (C) Jan Beskow \\
\hline
\end{tabular}

\section{Diskussion}

Metod. Avsikten är inte att åstadkomma generella beskrivningar av suicidala episoder. Avsikten är i stället att stödja Fp att upprätta en personlig och för henne giltig berättelse som leder fram till specifika kopingstrategier. Först i ett senare skede är det vår förhoppning att som i CREAM och DREAM kunna samla en stor mängd databeskrivna episoder, som kan användas till att urskilja speciella mönster och kan inspirera till preventiva åtgärder.

De viktigaste förändringarna i detta förhållningssätt jämfört med traditionell vård rör den suicidala personens egen medverkan på likvärdig nivå med klinikern/ forskaren; fokus på relativt korta episoder för analys och berättelse samt upprättandet av en individuell suicidpreventiv plan. Episodernas kroppsförnimmelser, känslor och handlingar flyter in i varandra (Rudd, 2006). Personens medvetenhet är kraftigt inskränkt. Dödens möjlighet gör episoden ångestladdad. Det är därför svårt och smärtsamt för den suicidala personen att treva sig fram till en för henne giltig förståelse och individuella preventiva åtgärder. Hennes psykiska plåga och djupt skakade självförtroende kräver full respekt från forskarens sida. Det hade varit enklare för både henne och mig att objektivera skeendet i från början fixerade termer, men sannolikt mindre givande för oss båda. En central upplevelse i den suicidala episoden, nämligen att vara utanför, inte duga, vara värdelös kan direkt motverkas genom en respekterad och likvärdig samverkan, som således kan ha en direkt suicidpreventiv effekt. Det första samtalet är här av avgörande betydelse.

Resultat. För mig som arbetat som psykiater inom suicidforskning och prevention i över 40 år har detta tillvägagångssätt inneburit nya erfarenheter, vilket ger det en viss face validity:

a) Jag har häpnat över den snabba kvalitativa skillnaden inom Fp från intellektuellt och emotionellt hög funktionsförmåga till den suicidala episodens undantagstillstånd;

b) Den episodiska suicidalitetens relativa lugn på nivå 0-2 samt dess blixtsnabba utveckling från nivå 3 och uppåt har också förvånat mig. 
Trots detta är förändringen möjlig att beskriva detaljerat i flera olika faser.

c) Särskilt viktig är utvecklingen från de tidigare skedenas synstörningar i form av otydlighet och dimma genom stadier präglade av mörker och intensiv kamp på liv och död, fram till den automatiserade slutfasen.

d) Hos denna Fp gick det att urskilja olika nivåer av triggers (trötthet/ depression; symboliskt våld såsom "skärande" musik samt bilder av en penetrerande penna och av skärsår; samt till sist upprepade relationsbesvikelser). Dessa utlöste i sin tur olika nivåer av kopingstrategier (stegvis hantering av yttre problem; kontaktförsök per telefon eller SMS; samt till sist kapitulation inför suicidimpulserna då hon var åtkomlig endast för räddning utifrån).

e) Forskning kring suicidala episoder kan bidra till utveckling av metoder för psykisk livräddning, motsvarande den kunskap som i dag finns kring fysisk livräddning (Beskow, 2007).

\section{Slutsatser}

Analys av suicidala episoder är ett känsligt område, som kräver speciell försiktighet. Fokuseringen på episoderna gav oväntad ny kunskap samt erfarenheter för vidare metodutveckling. Studien uppmuntrar till fortsatt arbete med denna inriktning.

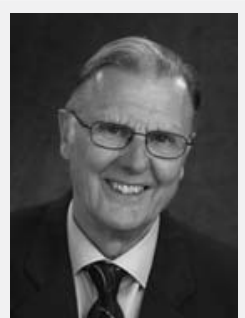

an Beskow är professor specialist i psykiatri och socialmedicin, suicidforskare, forskningschef vid Center för Cognitiv Psykoterapi och Utbildning i Göteborg samt vice ordförande i Västsvenska Nätverket för Suicidprevention. Hans senaste bok är Suicidalitetens språk, Studentlitteratur 2005 samt ett häfte om Psykisk Livräddning.

Västsvenska Nätverket för Suicidprevention, WNS, www.suicidprev.com

\section{Referenser}

Beck A.T. (1996). Beyond belief. A theory of mode, personality, and psychopathology. I:

Salkovskis $\mathrm{P}$ (red.). Frontiers of cognitive therapy. (s. 1-25). New York: Guilford Press.

Beskow J. (1983). Longitudinal and transactional perspectives on suicidal behaviour. Experiences of suicide prevention in Sweden. I: Achté K, Nieminen K, Vikkula J. (red.) Suicide Research II. Proceeding of the symposium on suicide research by the Yrjö Jahnsson foundation. Psychiatria Fennica 1982, suppl, 55-64, Helsinki.

Beskow J, Thorson J, \& Öström M. (1994) National suicide prevention programme and railway suicide. Soc Sci Med, 38 (3), 447-51.

Beskow J, Palm Beskow A, \& Ehnvall A. (2005) Suicidalitetens språk. Lund: Studentlitteratur.

Beskow J, \& Wikström L. (2007). Psykisk Livräddning. En första lektion för dig som tänker på självmord. Västsvenska Nätverket för Suicidprevention, WNS. Kan laddas ner från www.suicidprev.com

Beskow J, Salkovskis P, \& Palm Beskow A. (2009) Cognitive treatment for suicidal adults. I: Wasserman D, Wasserman C (red.). The Oxford textbook of suicidology and suicide prevention the five continents perspective. In press.

Casey P, Dunn G, Kelly BD, Lehtinen V, Dalgard OS, Dowrick C, \& Ayuso-Mateos J.L. (2008). The prevalence of suicidal ideation in the general population: results from the Outcome of Depression International Network (ODIN) study. Soc Psychiatry Psychiatr Epidemiol, 43 (4), 299-304.

Clark D., Beck A.T., Alford B. (1999). Scientific foundations of cognitive theory and therapy of depression. New York: Wiley.

Clarke R, \& Lester, D. (1989). Suicide: Closing the Exits. New York: Springer-Verlag.

Ellis TE (red). (2006). Cognition and suicide. Theory, research and therapy. Washington: American Psychological Association.

Foa E.B., \& Rothbaum B.O. (1998). Treating the trauma of rape. Cognitive-behavioral therapy for PTSD. London: The Guilford Press.

Holmes EA, Crane C, Fennell MJV, \& Williams JMG. (2007). Imagery about suicide in depression - "Flash-forwards"? Journal of Behavior therapy and Experimental Psychiatry, 38, 423-434.

Hollnagel E. (1998). Cognitive reliability and error analysis method - CREAM. Oxford: Elsevier Science.

Hollnagel E. (2004). Barriers and accident prevention. Burlington: Ashgate.

Jobes DA, \& Nelson KN. (2006). Shneidman's contributions to the understanding of suicidal thinking. Kap. 2 I: Ellis TE (red.) Cognition and suicide. Theories, research, and therapy.

Washington: American Psychological Association.

Kelly G. (1955). The psychology of personal constructs. New York: Norton \& Co.

Mehlum L. (1999). Tilbake til livet. Selvmordsforebygging i teori og praksis. Kristiansand: Høyskoleforlaget.

Ljung, M., Fagerlind, H., Lövsund, P., \& Sandin, J. (2007). Accident investigations for active safety at CHALMERS. New demands require new methodologies. Vehicle System Dynamics, 45 (10) 881-894.

Michel K. , Maltsberger J.T., Jobes D.A., Leenaars A.A., Orbach, I., Stadler K., Dey P., Young R.A., \& Valach L. (2002). Case study. Discovering the truth in attempted suicide. American Journal of Psychotherapy, 56, 424-37.

O'Connor, R.C., (2003). Suicidal behavior as a cry of pain. Test of a psychological model. Archives of Suicide Research, 7, 297-308.

Rasmussen J., Svedung I. (2006). Proactive risk management in a dynamic society. Karlstad: Swedish Rescue Services Agency, National Centre for Learning from Incidents and Accidents, $\mathrm{NCO}$ 2006:7.

Rudd M.D. (2000). The suicidal mode: A cognitive-behavioral model of suicidality. Suicide and Life-Threatening Behavior, 30, 18-33.

Rudd M.D., Joiner T., \& Rajab M.H. (2001).

Treating suicidal behavior. An effective, timelimited approach. London: The Guilford Press.

Rudd MD. (2006). Fluid vulnerability theory: A cognitive approach to understanding the process of acute and chronic suicide risk. I: Ellis TE (red.). Cognition and suicide. Theory, research and therapy. Washington: American Psychological Association.

Rådbo H. (2008). Systeminriktad prevention av järnvägssjälvmord. Strategiutveckling i en svensk kontext. Doktorsavhandling. Karlstad University Studies 2008:34

Shneidman E. (1985). The definition of suicide. New York: Wiley.

Stern D.(2005). Ögonblickets psykologi. Om tid och förändring i psykoterapi och vardagsliv. Stockholm: Natur och Kultur.

Teasdale JD (1988). Cognitive vulnerability to persistent depression. Cognition and Emotion 2 $247-74$

Waller J.A. (1980). Injury as a public health problem. I: Last, JM, Maxcy KF, Rosenau MJ (red.). Public Health and Preventive Medicine, 11th edition. New York: Appleton-Century-Crofts.

Williams M. (2001). Suicide and attempted suicide. Understanding the cry of pain. London: Penguin Books.

Williams J.M.G., Barnhofer T., Crane C., \& Beck A.T. (2005). Problem solving deteriorates following mood challenge in formerly depressed patients with a history of suicidal ideation. Journal of Abnormal Psychology, 114, 421-31.

Williams J.M.G., Crane C., Barnhofer T., Van der Does A.J.W., \& Segal Z.V. (2006). Recurrence of suicidal ideation across depressive episodes. Journal of Affective Disorders, 91, 189-94.

Öst LG (red.). (2006). KBT. Kognitiv beteendeterapi inom psykiatrin. Stockholm, Natur och Kultur. 